\title{
1 Licenciatura intercultural indígena como instrumento de efetivação de direitos humanos: notas sobre uma experiência didática
}

\author{
DIAS, Luciana de Oliveira ${ }^{1}$ \\ CERQUEIRA, lodenis Borges Figueira ${ }^{2}$
}

\section{Resumo}

Uma experiência de estágio docência, com enfoque em didática, acontecido no Núcleo Takinahakỹ de Formação Superior de Professores Indígenas da UFG, nos levou a reflexões, que compartilhamos agora, sobre alguns pontos do processo de constituição da educação intercultural indígena no Brasil e suas implicações em questões de direitos humanos. Em um primeiro momento destacamos elementos que conduzem a um protagonismo indígena nos processos de encontro e ampliação de saberes. Avançamos, em um segundo momento, analisando, de uma perspectiva da didática, o fazer pedagógico no curso de Educação Intercultural da UFG, com destaque para questões sobre interculturalidade, transdisciplinaridade e direitos humanos. O intuito mais específico neste ponto foi apresentar algumas notas sobre uma experiência didática na licenciatura em Educação Intercultural.

\section{Educação Intercultural Indígena. Direitos Humanos.}

\section{Indigenous intercultural degree as an instrument for the realization of human}

rights: notes on a didactic experience

\begin{abstract}
The reflections presented here derive from a teaching experience that took place at the Takinahakỹ Nucleus of Higher Education of Indigenous Teachers at UFG. With a focus on didactics, we now share these ideas about some aspects of the process of constitution of indigenous intercultural education in Brazil, as well as about their implications for human rights issues. In the first moment we highlight some elements that lead to an indigenous protagonism in the processes of encounter and expansion of knowledge. In a second moment, we proceeded to analyze, from a didactic perspective, the pedagogical achievement in the UFG Intercultural Education course, with emphasis on questions on interculturality, transdisciplinarity and human rights. The most specific purpose in this point was to present some notes about a didactic experience in the course of teacher training in Intercultural Education.
\end{abstract}

Indigenous Intercultural Education. Human rights.

\footnotetext{
${ }^{1}$ Antropóloga, doutora em Ciências Sociais pela Universidade de Brasília - UnB. Professora da Licenciatura em Educação Intercultural Indígena e do Mestrado Interdisciplinar em Direitos Humanos da Universidade Federal de Goiás - UFG. E-mail: professoralucianadias@gmail.com ${ }^{2}$ Mestranda em Direitos Humanos, pela Universidade Federal de Goiás - UFG. E-mail: iodenesborges@yahoo.com.br
} 
O texto que ora apresentamos é resultado da experiência de estágio docência, com enfoque na didática, da mestranda do Programa de Pós-Graduação Interdisciplinar em Direitos Humanos, da Universidade Federal de Goiás - UFG, lodenis Cerqueira, sob a orientação da professora Luciana Dias. O estágio aconteceu na licenciatura em Educação Intercultural Indígena, da UFG, durante o segundo semestre de 2017. Este manuscrito tem o objetivo de apresentar, compartilhar e problematizar a concretização de uma prática pedagógica no ensino superior e também, sobretudo, realizar algumas reflexões acerca de percursos, anseios, conquistas e resistências quanto à formulação e efetividade de direitos, no campo da educação, aos povos originários no Brasil.

Para alcançar esses objetivos, iniciamos as discussões apresentando alguns pontos do processo de constituição da educação intercultural indígena no Brasil. Um processo que articula pressões exercidas pelos movimentos sociais sobre o poder público, demandas pela efetivação de direitos sociais, políticos, civis, enfim, direitos humanos, e, processos de constituição e fortalecimento das identidades diante de investidas colonizadoras que recaíram sobre a educação indígena. O protagonismo indígena confere agência aos indígenas na construção da educação que desejam e na elaboração de novas epistemologias, por meio da fusão de horizontes epistêmicos, com potencial para inaugurar cenários de efetiva realização de direitos humanos, no campo da educação.

Com o intuito de avançar nas reflexões pretendidas, apresentamos discussões sobre uma experiência de estágio docente, com enfoque na didática, acontecida no âmbito da licenciatura em Educação Intercultural de Formação Superior de Professores Indígenas da UFG. Neste tópico estão apresentadas discussões sobre a didática e seu potencial transformador; interculturalidade e sua capacidade de ampliação de horizontes epistêmicos ${ }_{1}$ pelos encontros acontecidos; transdisciplinaridade como uma possibilidade de apresentarem os múltiplos saberes, na ampliação de conhecimentos; e afirmação das identidades, por meio da realização da igualdade e reconhecimento da diferença, como instrumentos na luta pela efetivação de direitos. 
O curso de graduação em Educação Intercultural Indígena, uma licenciatura da UFG está abrigado no Núcleo Takinahakỹ de Formação Superior de Professores Indígenas da UFG e conta hoje com representantes de mais de vinte povos indígenas compondo seu corpo discente, quais sejam: Apinajé, Bororo, Canela, Gavião, Guajajara, Javaé, Juruna, Kayapó, Kamaiurá, Karajá, Krahô, Krikati, Kuikuro, Tapirapé, Tapuia, Timbira, Xakriabá, Xambioá, Xavante, Xerente, Waurá, Yawalapiti, perfazendo neste ano de 2018 um total de 281 estudantes. Esses estudantes são também docentes do ensino básico em suas aldeias.

O curso, que começou a funcionar em 2007, visa formar docentes indígenas, objetivando atender a uma demanda das comunidades indígenas no que se refere à formação superior de seus docentes. A proposta curricular do curso, que conta com ações presencias na UFG (duas vezes ao ano) e nas aldeias (também duas vezes ao ano), apresenta uma estrutura composta por dois anos iniciais de Matriz Básica e três anos finais de Matriz de Formação Específica na qual os estudantes escolhem aproximar seus estudos de uma das três áreas específicas do curso, quais sejam: Ciências da Cultura, Ciências da Linguagem ou Ciências da Natureza.

O curso pode ser integralizado pelo estudante com cinco anos de estudos e é destinado a indígenas aldeados que demandam por definição de ações de defesa de seus direitos, por adoção de políticas de manutenção de suas línguas e culturas maternas e de suas terras, e, por um delineamento de políticas de desenvolvimento sustentável. A pluralidade cultural e o respeito à diferença têm guiado as ações no âmbito da Educação Intercultural, que apresenta como eixos epistemológicos: a interculturalidade, que além do encontro de culturas provoca também o encontro de saberes; e a transdisciplinaridade, que problematiza e amplia a concepção de disciplina por meio de uma proposta de reconhecimento da pluralidade e geração de complementaridade entre saberes.

\section{Processo de constituição da educação intercultural indígena no Brasil}

Diante da articulação dos povos indígenas brasileiros para mudar sua condição de exploração e dominação advindas com o processo de colonização, foise delineando uma série de reivindicações em prol da emancipação social, da constituição de autonomia e de possibilidades de criação e acesso a mecanismos garantidores de novas possibilidades de existência nas mais variadas áreas. Nesse contexto histórico de articulações, a Constituição Federal de 1988 emergiu como um importante marco jurídico que representa um processo mais amplo de busca de novas perspectivas acerca dos povos indígenas e também de suas demandas. Resultado da pressão dos mais variados movimentos sociais pelo reconhecimento 
de direitos, e em um cenário de políticas públicas específicas, urge a necessidade de definir, identificar e assumir um pertencimento étnico.

Sobre os processos de identificação, Tomaz Tadeu da Silva (2000, p. 81), pontua que, tanto a identidade quando a diferença, são criadas no campo social e cultural sendo que, desta forma, "a afirmação da identidade e a enunciação da diferença traduzem 0 desejo dos diferentes grupos sociais, assimetricamente situados, de garantir o acesso privilegiado aos bens sociais". Portanto, as articulações dos povos indígenas, juntamente com o apoio de setores da sociedade civil por demanda de direitos vão ao encontro da representação do reconhecimento à diferença com a promulgação da Constituição de 1988,

[...] o diploma constitucional quebrou o paradigma da integração e da assimilação que até então dominava o nosso ordenamento jurídico, determinando-lhe um novo rumo que garanta aos povos indígenas permanecerem como tal, se assim o desejarem, devendo o Estado assegurar-Ihes as condições para que isso ocorra (ARAÚJO, 2014 p. 45).

A partir dessas premissas iniciais, a educação indígena pode ser compreendida como um potencial instrumento de colaboração para a autonomia desses povos autóctones. Enfatizamos que a construção da autonomia tem se destacado como principal bandeira de luta dos povos indígenas no Brasil nos seus mais variados campos de atuação. Conforme o Referencial Curricular Nacional para Escolas Indígenas (1998), ao prezar por uma educação intercultural, comunitária, específica e diferenciada, tendo como protagonistas os próprios indígenas, torna-se possível abrir caminhos para uma educação mais autônoma, que valorize o pertencimento étnico, as línguas e culturas tão diversas.

Ao tratar especificamente da Educação Indígena, nos indagamos em um primeiro momento sobre a necessidade de problematizar os significados atribuídos à educação escolar indígena. Problematizar a própria concepção de escola se faz necessário, tendo em vista que a noção de educação indígena está para além de um sistema escolar que esteja pautado na transmissão de conhecimentos e processos educativos com base nas tradições orais e socialização dos indivíduos em todas as etapas da vida. Se faz oportuno destacar o resultado das ações dos movimentos políticos e sociais organizados que buscam a garantia e efetivação dos direitos humanos mais fundamentais.

Ao acessar analiticamente esse contexto, foi preciso recorrer a uma perspectiva histórica tendo como objetivo primordial o interesse em compreender quais são e como se dão as significações da escola pelos próprios indígenas que a frequentam na condição de docentes ou de discentes. Neste exercício de alteridade radical (PEIRANO, 1999), devemos estar cientes de que o projeto colonizador inseriu uma proposta de educação voltada à subjugação das culturas e povos 
indígenas, a escola foi um importante instrumento aliado a projetos de assimilação, pacificação e integração dos povos indígenas à sociedade nacional.

Destacamos aqui as políticas indigenistas do período colonial que se pautaram pela perspectiva de uma educação missionária a partir da catequese como possibilidade de "civilizar" os povos indígenas e gradativamente levar a uma substituição de suas culturas, por meio da aculturação via processo de alfabetização escolar (PERRONE-MOISÉS, 1992). Entre tantos interesses, se destaca o que diz respeito à anexação dos territórios e ampliação do acesso dos colonizadores em lugares nos quais os indígenas eram uma resistência, cada vez mais politizada, à efetivação do projeto colonizador.

É importante citar que os contextos posteriores foram marcados por tentativas de pacificação dos povos indígenas por meio da criação de uma política de constituição de aldeamentos em que a igreja, através da educação escolar catequizadora e as repartições militares com uso da força, impuseram aos povos indígenas valores da cultura ocidental, baseados em uma moral cristã assimilacionista (PERRONE-MOISÉS, 1992).

Era preciso "eliminar os vícios que poluíam suas almas", eliminar e/ou silenciar complexas lógicas e racionalidades que se confrontavam (e resistiam) à cultura ocidental-europeia, branca, cristã, individualista, competitiva e excludente. Estas políticas tiveram o intuito de integrar esses povos, compensando suas "deficiências" e silenciando suas diferenças. (SILVA, 2007, p. 95).

Buscando um avanço reflexivo a partir da consideração de realidades como essas podemos afirmar, de maneira categórica, que a escrita, pontualmente a que foi imposta aos povos indígenas, é carregada de significados e intencionalidades. Não há como desprezar o entendimento de que a língua carrega um grande arsenal simbólico na medida em que a mesma abriga e veicula valores da cultura da sociedade envolvente que se quer hegemônica e dominante. Tomando essas considerações como pano de fundo, pode ser observado que a inserção dos povos indígenas no modelo de educação brasileiro se deu por meio da introdução da escola e da escrita. Enfatizamos, todavia, que essa inserção não conseguiu assegurar autonomia, cidadania ou mesmo uma condição de portadores de culturas, de princípios e de valores diferenciados característicos dos povos indígenas.

Até meados do século $\mathrm{XX}$, o princípio assimilacionista, que pressupõe a assimilação das culturas marginalizadas pelas culturas dominantes, permeou os projetos da política indigenista também no campo da educação. Os movimentos sociais organizados e as novas demandas que emergiram nesse contexto político propiciaram a partir da década de 1980 uma proposta de educação escolar dos povos indígenas que levasse em consideração o bilinguismo. Deste modo, ante o processo de organização para a Constituinte, os povos indígenas e sociedade civil 
organizada conquistaram a garantia na Constituição brasileira de reconhecimento do pluriculturalismo, que informa sobre a multiplicidade de culturas, e das diferenças étnicas e linguísticas, que permitem realçar as singularidades dos pertencimentos.

Sobre o reconhecimento das diferenças étnicas e linguísticas, vale enfatizar sua impactante contribuição com processos de desconstrução de noções estigmatizantes que permitiram durante séculos, que uma concepção de índio genérico fosse acionada sempre que se deparasse com alguma das centenas de possibilidades de existência indígena. É a partir da década de 1980 e da consideração do bilinguismo que reconhecimentos como o das diferenças étnicas que se principia uma autonomia aos povos indígenas brasileiros. Assim sendo,

Com a constituição de 1988, assegurou-se aos índios no Brasil o direito de permanecerem índios, isto é, de permanecerem eles mesmo, com suas línguas, culturas e tradições. Ao reconhecer que os índios poderiam utilizar suas línguas maternas e seus processos de aprendizagem na educação escolar, institui-se a possibilidade de a escola indígena contribuir para o processo de afirmação étnica e cultural desses povos, deixando de ser um dos principais veículos de assimilação e integração (BRASIL, 2002, p. 9).

Desde então a educação escolar indígena tem se consolidado como uma modalidade de ensino que tem suas bases alicerçadas nos pilares da interculturalidade e do bilinguismo. O que, por sua vez, faz com que a educação escolar indígena vá ano após ano alcançando seu caráter de educação diferenciada, o que permite que ela se contraponha a propostas hegemônicas de educação escolar.

Resultante da mobilização de movimentos sociais e políticos que empreenderam lutas em prol da educação indígena autônoma e reivindicaram direitos específicos e diferenciados aos povos indígenas, experimentamos neste século XXI problematizações profundas que contrariam qualquer perspectiva de matriz cultural única. Ao analisarmos normativas legais, tais quais: as Diretrizes Internacionais, a Constituição Federal de 1988, a Lei de Diretrizes e Base da Educação Nacional de 1996, os Parâmetros Curriculares Nacionais de 1998, ou as Diretrizes Curriculares para a Educação Escolar Indígena, todas elas referentes a essa alternativa educacional, observamos a importância do protagonismo indígena que tem sido observado nos últimos tempos.

É esse protagonismo indígena - que assegurou que organizações e movimentos que reivindicaram, e ainda reivindicam autonomia na condução de seus projetos, bem como respeito a suas especificidades culturais frente à sociedade nacional - o principal agente na elaboração de aspectos teóricos e conceituais (históricos, antropológicos e pedagógicos), que são também epistêmicos e com tendências à transdisciplinaridade. Essa rápida digressão histórica presente nesta 
sessão do texto nos instrumentaliza a afirmar que a interculturalidade e a transdisciplinaridade, ao assegurarem o bilinguismo e a autonomia na construção da educação indígena, devem ser os eixos orientadores de uma educação escolar indígena com potencialidade para a efetiva realização de direitos fundamentais aos povos indígenas.

\section{Notas sobre uma experiência didática na licenciatura em Educação Intercultural Indígena da UFG}

A formação de professores indígenas é de fundamental importância para concretização de inúmeras mudanças e transformações, e também para a realização de direitos elementares e constituição de "cidadanias diferenciadas" (BANIWA, 2006, p. 89), o que significa que "os povos indígenas, além do usufruto dos direitos universais do cidadão brasileiro ou planetário, possuem também o usufruto dos direitos específicos relativos à sua cultura, às tradições, aos valores, aos conhecimentos e aos ritos". Esta formação deve estar de acordo com os anseios de cada povo, devendo também contribuir com a educação escolar e não escolar, já que há um compromisso com cosmologias diferentes da hegemônica. É neste sentido que a licenciatura em Educação Intercultural Indígena da UFG busca constituir-se como um espaço de construção e encontro de saberes que, juntos, forjam novas nuances de possibilidades de ser, de existir, de interagir e de resistir para os povos indígenas.

Conforme previsto no Projeto Político Pedagógico - PPP, da Educação Intercultural Indígena da UFG, o objetivo da referida licenciatura é a formação de docentes indígenas para que estes possam lecionar nas escolas de suas aldeias. Importante chamar a atenção para o fato de que esta é uma demanda dos próprios indígenas que a Educação Intercultural se empenha em colaborar no atendimento. De acordo com o PPP do curso: "com a formação proposta pelo curso ora apresentado, o professor formado será não apenas um especialista, mas um profissional capaz de contribuir com a melhoria do ensino em sua comunidade" (PPP, 2006, p. 11).

Perante a busca por efetivação de direitos e a consequente formação social, política e identitária dos povos originários brasileiros, uma proposta de educação intercultural deve emprenhar-se em contribuir com uma formação superior crítica. Deste modo, os estudantes tornam-se protagonistas, com a colaboração dos demais sujeitos do ambiente educacional, de sua própria formação. Todo o processo educacional, em uma perspectiva intercultural, deve fazer com que os estudantes "se tornem sujeitos ativos de sua própria aprendizagem" (LIBÂNEO, 2002, p. 6).

José Carlos Libâneo (2002) compreende que a didática versa sobre elementos que proporcionam a realização do processo de ensino, afirmando ser por 
meio da contribuição das ciências da educação que a didática é constituída. Ao identificar que o ensino de um campo disciplinar não basta partir de somente um único ponto do conhecimento, Libâneo (2002, p. 12) elucida que "a tarefa de ensinar requer do professor conhecimentos e práticas que vão mais além do fato de ele ser um especialista em história", por exemplo.

Diferente das metodologias de ensino que possuem o foco em análises de propostas de ensino, de uma matéria, a didática perpassa diversos campos dos saberes, vez que esta "abstrai as particularidades das distintas matérias e generaliza as manifestações e leis específicas do ensino e aprendizagem nas diferentes disciplinas e formas de ensino" (LIBÂNEO, 2006, p. 13). Ainda com relação à didática, e em um diálogo mais estreito com Paulo Freire (1996), compreendemos que o saber didático não se limita a um campo específico ou a determinada disciplina de um currículo, o saber didático trata de uma educação para a liberdade, que constrói a autonomia e consiste na articulação de um conjunto de saberes fundamentais à prática educativa transformadora.

A partir dessas concepções e levando em consideração o quanto o ambiente educativo é formado por uma diversidade de estudantes, com sistemas de cognição diferentes, estruturas familiares distintas, cosmologias e cosmovisões particulares, é necessário prezar por uma didática que consiga dialogar com todas as diferenças e demandas possíveis. A escuta aberta e a percepção ampliada das alteridades são instrumentos importantíssimos que propiciam o ensino e aprendizagem com o apelo a uma didática dialógica e crítica. Libâneo (2002, p. 17) nos lembra ainda que a didática "se enriquecerá mais quanto mais der conta de postular o que lhe é específico e, a partir daí, explorar as fronteiras e zonas intermediárias do conhecimento cientifico".

No âmbito da Educação Intercultural Indígena da UFG, em consonância com os pontos que estamos discutindo aqui sobre a didática, a interculturalidade e a transdisciplinaridade são princípios orientadores da prática educativa que ali se realiza. Catherine Walsh (2009) estuda a interculturalidade, com ênfase no campo educativo, como sendo um potente e criativo projeto político de descolonização e transformação. Neste sentido, para a pensadora que se inspira em Paulo Freire, a educação intercultural somente terá sentido, significação, impacto e valor quando assumida de maneira crítica e enquanto um projeto político. O esforço que pode ser notado no Núcleo Takinahakỹ indica para essa concepção de interculturalidade, que presume uma dimensão relacional entre diversas culturas manifestas na educação e assumidas criticamente, dando contornos a um projeto político, pedagógico, social, epistêmico e ético.

Vera Maria Candau (2008, p. 51) compreende a interculturalidade como sendo a "promoção deliberada da inter-relação entre diferentes grupos culturais presentes em uma determinada sociedade". Neste sentido, conceber as culturas como dinâmicas, propensas a constantes mudanças e não como fixas, imutáveis, 
implica eliminar a visão hegemônica de cultura. Já a interdisciplinaridade é entendida por Olga Pombo (2003) como uma convergência de pontos de vista e/ou complementaridade de algo, afirmando ser esta uma combinação de compreensões diversas. No que diz respeito à transdisciplinaridade, a filósofa portuguesa a definiu como "algo que se aproximasse de um ponto de fusão, de unificação, quando fizesse desaparecer a convergência, nos permitiria passar a uma perspectiva holista" (POMBO, 2003, p. 5). Desta forma, ante a necessidade de integração de disciplinas em torno de um assunto comum, a autora nos coloca que,

Mesmo que a ciência tenha seguido um modelo de especialização, a escola e a universidade, nomeadamente através dos seus regimes curriculares e metodologias de trabalho, devem defender perspectivas transversais e interdisciplinares. E isto por quê? Porque é da presença na consciência do investigador de várias linguagens e de várias disciplinas que pode resultar o próprio progresso científico. Ou seja, porque há uma heurística que resulta justamente dessa formação interdisciplinar (POMBO, 2003, p. 13).

Para tanto, a não hierarquização do conhecimento é característica fundamental para que se consiga realizar, de fato, uma formação transdisciplinar e intercultural, vez que, é através do diálogo entre, de um lado, o conhecimento dos povos indígenas e de outro, o conhecimento científico-acadêmico que acontece o encontro de saberes, seja para complementar, atualizar ou para unificar determinado tema. Ainda sobre a transdisciplinaridade, importante destacar que uma atitude com este enfoque permite uma abertura à criatividade provocada pelo encontro intercultural respeitoso e descolonial, que cultiva a lucidez e a ousadia.

O estágio docência que fora realizado no Núcleo Takinahakỹ, na etapa de estudos na UFG, em julho e agosto de 2017, intentou levar à compreensão os contornos de uma prática didática em um ambiente de educação intercultural e transdisciplinar. As aulas que se desenvolveram versaram sobre o tema contextual "Cultura e Trabalho" e aconteceram em uma turma com os estudantes recém ingressos na UFG. O esforço em realizar a transdisciplinaridade pede que rupturas com concepções herméticas de disciplinas aconteçam. Assim sendo, a ideia de disciplinas é evitada e o empenho é por construir conjuntamente um tema contextual que atenda às expectativas de aprendizado dos estudantes em parceria com os docentes nos instantes de aulas.

Um grupo de estudantes e docentes extremamente intercultural, com uma diversidade de pertencimentos étnicos, culturais e linguísticos tem proporcionado encontros intensos entre saberes, e não raras vezes, uma espécie de transcendência de conhecimentos. Um aprofundamento acerca do que seja "cultura e trabalho" foi adquirido a partir de uma acentuada diversidade de narrativas sobre o tema, o que permite uma aproximação de dimensões inalcançáveis em contextos disciplinares. O que se exercita nesses ambientes de ensino e aprendizagem é um 
acionamento de locais de fala que partem de vivências de povos que possuem línguas diversas, costumes e crenças distintas e residem em estados e regiões diferentes do Brasil.

A diversidade cultural, linguística, epistemológica e cosmológica representada em um mesmo espaço tem nos levado, no Núcleo Takinahakỹ, a perceber o absurdo que há em uma concepção de índio genérico. Há distâncias oceânicas entre, por exemplo, um estudante tapuia e uma estudante gavião e a alteridade é sempre radical, o que faz com que os saberes sejam dialógicos e ampliados exponencialmente. Potencialidades geridas por alteridades que se colocam de maneira respeitosa e responsável assumindo suas idiossincrasias, sem abandonar a possibilidade de afirmação de uma categoria identitária única, como indígenas aproximando todos os povos, em situações de luta pela realização de direitos humanos.

Diante de uma interculturalidade assumida como projeto político e tendo como eixo orientador a transdisciplinaridade, os momentos de ensino e aprendizagem durante os temas contextuais extrapolam as aulas. O Núcleo Takinahakỹ, por meio de seus estudantes-professores indígenas e docentes tem investido muita energia na produção de materiais didáticos que tem atendido as escolas indígenas e também tem servido de base para as aulas que acontecem no Núcleo Takinahakỹ. Evidencia-se uma prática didática transformadora de realidades e amplificadora de saberes. Somos levadas, mais uma vez, a concordar com o que afirma Paulo Freire (1996, p. 15) quando enfatiza que "ensinar exige respeito aos saberes dos educandos".

Quanto ao material que vem sendo produzido, no formato de livros didáticos ou não, cartilhas e materiais ilustrados, coletâneas com organização conjunta entre estudantes e docentes, sendo a maioria deles bilíngue, o que pudemos observar é que os saberes são alargados, registrados e difundidos, forçando mudanças por todos os lugares nos quais se inserem. São notórias as transformações no curso do Núcleo Takinahakỹ com ampliação de conhecimentos de professores e estudantes; transformações nas aldeias e nas escolas das aldeias onde vivem, com a revitalização e revalorização de saberes; e, transformações na UFG que tem sido obrigada a se reposicionar diante de conhecimentos hierarquizados e extremamente disciplinares que mais reduzem do que ampliam possibilidades compreensivas e explicativas.

Chamamos a atenção para o fato de que os estudantes-professores indígenas que se formam no Núcleo Takinahakỹ passam a se responsabilizar respeitosamente pelos processos de ensino e aprendizagem nas escolas de suas aldeias, onde são professores. Concomitantemente, passam a assumir papéis estratégicos e lugares de liderança dentro de suas comunidades, sobremaneira se posicionando à frente dos desafios de implementar uma proposta de educação diferenciada, intercultural, bilíngue e transdisciplinar. Durante as aulas na UFG são 
muitos os estudantes indígenas que destacam e pedem por debates aprofundados sobre questões, conflitos e problemáticas que enfrentam em suas comunidades e para os quais estão à busca de respostas e resoluções que muitas vezes são alcançadas coletivamente.

Refletir acerca da Educação Intercultural da UFG, apreendida como uma proposta didática transformadora eminentemente intercultural e transdisciplinar, significa também abordar a relação entre igualdade e diferença. Embora a igualdade tenha sido símbolo de luta por direitos, Vera Maria Candau (2008) identifica uma mudança na demanda. Não que a autora queira dizer que "se nega a igualdade, mas que se coloca muito mais em evidência o tema da diferença" em tempos recentes (CANDAU, 2008, p. 46). Essa discussão é importante porque se observa no Núcleo Takinahakỹ a afirmação de identidades, e estas que nos levam a pensar na relação entre igualdade e na diferença.

Para Boaventura de Sousa Santos (2003), existe certa dificuldade entre reconhecer a diferença e a igualdade, motivo pelo qual formulou a máxima de que "temos o direito a ser iguais quando a diferença nos inferioriza e temos o direito a ser diferentes quando a igualdade nos trivializa" (SANTOS, 2003, p. 56). Assim sendo, tanto a igualdade quanto a diferença convertem-se em direitos. A aplicabilidade do princípio da igualdade, com o intuito de equilibrar as relações e o tratamento dispensado a diversos seguimentos, inclusive no sentido de redistribuição de bens, transformou-se em luta para reduzir as desigualdades socioeconômicas tão latentes no Brasil, haja vista que

\begin{abstract}
A ideia do fundacional/identitário passou a disputar o monopólio da ideia do universal/igualitário até então incontestado. A partir de então a luta contra a discriminação e a exclusão deixou de ser uma luta pela integração e pela assimilação na cultura dominante e nas instituições suas subsidiárias, para passar a ser uma luta pelo reconhecimento da diferença, pela consequente transformação da cultura e das instituições de modo a separar as diferenças (a respeitar) das hierarquias (a eliminar) que atavicamente thes estavam referidas (CHAUÍ; SANTOS, 2013, p. 79).
\end{abstract}

Cabe também ressaltar como um importante instrumento, a elaboração da Declaração Universal dos Direitos Humanos de 1948, da qual derivaram inúmeros tratados e legislações acerca do tema. Entretanto, cabe levantar a seguinte problemática: Os direitos humanos são para quem? E os direitos humanos são constituídos com a perspectiva de que cultura? Esta Declaração Universal foi formulada "sem a participação da maioria dos povos do mundo; no reconhecimento exclusivo de direitos individuais, com a única excepção do direito colectivo à autodeterminação, o qual, no entanto, foi restringido aos povos subjugados pelo colonialismo europeu" (CHAUÍ; SANTOS, 2013, p. 45). Importante destaque, com o qual nos alinhamos. 
Deste modo, no Brasil está naturalizada a reprodução da ideia de que "somos iguais". Vale destacar que essa afirmativa é uma estratégia eficiente de um discurso que quer negar que alguns segmentos sociais tenham tratamento inferior em relação a outros. Se levarmos em consideração que o princípio da isonomia estabelece que todas as pessoas são iguais perante a lei, temos que admitir o engodo na interpretação deste princípio, uma vez que o mesmo ressalta que o tratamento jurídico deve ser assegurado a todos e não que as pessoas são iguais. Clareza conceitual acerca da igualdade e da diferença nos coloca frente a frente aos complexos processos de constituição das identidades que, nos atinando especificamente ao tema central tratado neste texto, são consolidados também no Núcleo Takinahakỹ da UFG.

\section{Algumas considerações}

A luta pela igualdade e o reconhecimento da diferença conduzem a uma reafirmação contínua das múltiplas identidades indígenas. Esses povos, ao positivarem seus modos de vida e afirmarem suas identidades provocam melhorias em todos os setores de sua vida, inclusive no ensino escolar de suas aldeias. Há uma espécie de apropriação da escola que é ressignificada e conduz a um empoderamento dos povos indígenas. Os professores e professoras indígenas formados no Núcleo Takinahakỹ, tem a possibilidade de refletir sobre suas concepções de educação pautadas em uma perspectiva de construção coletiva e com caráter específico, diferenciado, intercultural, transdisciplinar, sustentável e plurilíngue.

No estado democrático de direito, o fato de que somos iguais perante a ótica jurídica, não anula as diferenças étnico-raciais, culturais, religiosas, de gênero, dentre muitas outras. Significa dizer que em uma sociedade, como a brasileira, as relações de poder estão marcadas por relações de forças que, intencionalmente, elegem características que são determinantes para inferiorizar ou exaltar o outro. Essas relações de poder são evidenciadas e profundamente discutidas no âmbito da Educação Intercultural da UFG. A ideia é conhecer, desde uma didática emancipatória, para transformar uma realidade que segue reproduzindo mecanismos de opressão a sujeitos subalternizados em pleno século XXI.

A afirmação positivada de identidades de cada um dos indivíduos e povos que compõem o Núcleo Takinahakỹ; a formação e capacitação de docentes indígenas em um curso superior na UFG; a realização dos temas contextuais que demandam por pesquisas robustas que são desenvolvidas semestre após semestre nas aldeias; as lideranças que se constituem e passam a atuar nas comunidades indígenas, nos mais variados campos e não somente no campo da educação; as articulações interculturais acontecidas durantes as etapas de estudos seja nas aldeias, seja na UFG; os intensos processos de revitalização das culturas e das línguas que decorrem das experiências vivenciadas na Educação Intercultural; as inúmeras 
produções bibliográficas e materiais didáticos que materializam percepções e não auto percepções indígenas mais livres de estigmas e marcadamente decoloniais; além de inúmeras outras ações, evidenciam as impactantes transformações que estão em curso.

São essas transformações que tem permitido trilhar caminhos em direção à concretização de direitos fundamentais aos povos indígenas. O reconhecimento das diferenças e a busca por garantia de igualdade aliadas à luta por uma educação diferenciada, transdisciplinar, intercultural e específica para os povos indígenas têm levado à constituição de uma cidadania diferenciada que é eminentemente plural e múltipla, já que deve assegurar o direito à cultura indígena e à cultura brasileira, ou planetária, na qual os povos indígenas conquistam o direito de perpetuar e atualizar seus próprios modos de vida, seus princípios, valores, culturas e línguas, sem perderem o direito de acesso a outras tantas culturas, valores, princípios, modos de vida, línguas e tecnologias.

\section{Referências}

ARAÚJO, Ana Valéria et all. Povos Indígenas e a Lei dos "Brancos": o direito à diferença. Brasília: Ministério da Educação, Secretaria de Educação Continuada, Alfabetização e Diversidade; LACED/Museu Nacional, 2006.

BANIWA, Gersem dos Santos Luciano. O Índio Brasileiro: o que você precisa saber sobre os povos indígenas no Brasil de hoje. Brasília: Ministério da Educação, Secretaria de Educação Continuada, Alfabetização e Diversidade; LACED / Museu Nacional, 2006.

BRASIL. Congresso Nacional. Constituição Federal da República Federativa do Brasil. Brasília, 1988.

Ministério da Educação. Referencial Curricular Nacional para as Escolas Indígenas. Brasília: MEC/SEF, 1998.

Ministério da Educação. Educação Escolar Indígena. As Leis e a Educação Escolar Indígena. Brasília, 2002.

CANDAU, Vera Maria. Direitos Humanos, educação e interculturalidade: as tensões entre igualdade e diferença. Revista Brasileira de Educação, v. 13, n. 37, jan./abr. 2008.

CHAUÍ, Marilena; SANTOS, Boaventura de Sousa. Direitos humanos, democracia e desenvolvimento. São Paulo: Cortez, 2013.

FREIRE, Paulo. Pedagogia da Autonomia: saberes necessários à prática educativa. São Paulo: Paz e Terra, 1996.

LIBÂNEO, José Carlos. Didática - Velhos e novos temas. Goiânia, Edição do autor. 2002.

PEIRANO, Mariza G. S. A Alteridade em Contexto: A Antropologia como Ciência Social no Brasil. Série Antropologia, no 255, Brasília, 1999. 
PERRONE- MOISÉS, Beatriz. Índios livres e índios escravos: os princípios da legislação indigenista do período colonial (séculos XVI a XVIII) In: CUNHA, Manuela Carneiro da (org.). História dos índios no Brasil. São Paulo: Companhia das Letras, 1992.

POMBO, Olga. Epistemologia da Interdisciplinaridade. In: Seminário Internacional Interdisciplinaridade, Humanismo, Universidade. Porto: Universidade do Porto, 2003. Disponível em: <http//www.humanismolatino.online.pt/vl/pdf/C002_11.pdf>

PPP. Projeto Político Pedagógico da Licenciatura Intercultural. Universidade Federal de Goiás. Faculdade de Letras. Núcleo Takinahakỹ de Formação Superior Indígena. Goiânia: UFG, 2006.

SANTOS, Boaventura de Souza. Por uma concepção multicultural de direitos humanos. In: Reconhecer para libertar: os caminhos do cosmopolitismo multicultural. Rio de Janeiro: Civilização Brasileira, 2003.

SILVA, Rosa Helena Dias da. Inclusão e políticas afirmativas em educação para um Brasil pluricultural: reflexões sobre povos indígenas e ensino superior. Porto Alegre, $\mathrm{n}$. 1(61), jan./abr. 2007, p. 93-107.

SILVA, Tomaz Tadeu (org.). Identidade e Diferença: a perspectiva dos estudos culturais. Rio de Janeiro: Editora Vozes, 2000.

WALSH, Catherine. Interculturalidad crítica y educación intercultural. 2009.

(Conferência apresentada no Seminário "Interculturalidad y Educación Intercultural", Instituto Internacional de Integración del Convenio Andrés Bello, La Paz). Disponível em: <http://docplayer.es/13551165-Interculturalidad-critica-y-educacion-intercultural.html>. Acesso em: junho de 2017. 